\title{
Splash M-knife versus Flush Knife BT in the technical outcomes of endoscopic submucosal dissection for early gastric cancer: a propensity score matching analysis
}

Mitsuru Esaki ${ }^{1,2^{*}}$ (D) Sho Suzuki ${ }^{1}$, Yasuyo Hayashi², Azusa Yokoyama², Shuichi Abe ${ }^{2}$, Taizo Hosokawa², Haruei Ogino ${ }^{2,3}$, Hirotada Akiho ${ }^{2}$, Eikichi Ihara ${ }^{3}$ and Yoshihiro Ogawa ${ }^{3}$

\begin{abstract}
Background: Endoscopic submucosal dissection (ESD) is a standard treatment for early gastric cancer. A new multifunctional ESD device was developed to achieve complete ESD with a single device. A metal plate attached to its distal sheath achieves better hemostasis during the procedure than the other needle-knife device, Flush Knife BT ${ }^{\oplus}$, that has been conventionally used. The aim of this study was to compare the technical outcomes of ESD for early gastric cancer using the Splash M-Knife ${ }^{\circledast}$ with those using the Flush Knife BT.
\end{abstract}

Methods: We conducted a retrospective review of the case records of 149 patients with early gastric cancer treated with ESD using the needle-type ESD knives between January 2012 and August 2016 at Kitakyushu Municipal Medical Center. Lesions treated with ESD using the Splash M-knife (ESD-M) and the Flush Knife BT (ESD-F) were compared. Multivariate analyses and propensity score matching were used to compensate for the differences in age, gender, underlying disease, antithrombotic drug use, lesion location, lesion position, macroscopic type, tumor size, presence of ulceration, operator level and types of electrosurgical unit used. The primary endpoint was the requirement to use hemostatic forceps in the two groups. The secondary endpoints of procedure time, en bloc and complete resection rates, and adverse events rates were evaluated for the two groups.

Results: There were 73 patients in the ESD-M group, and 76 patients in the ESD-F group. Propensity score matching analysis created 45 matched pairs. Adjusted comparisons between the two groups showed a significantly lower usage rate of hemostatic forceps in the ESD-M group than in the ESD-F group (6.7\% vs $84.4 \%, p<0.001)$. Treatment outcomes showed an en bloc resection rate of $100 \%$ in both groups; complete resection rate of $95.6 \%$ vs $100 \%, p=0.49$; median procedure time of 74.0 min vs $71.0 \mathrm{~min}, p=0.90$; post-procedure bleeding of $2.2 \%$ vs $2.2 \%, p=1$, in the ESD-M and ESD-F groups, respectively. There were no perforations in either group.

Conclusions: ESD-M appeared to reduce the usage of hemostatic forceps during ESD for early gastric cancer without increasing the adverse effects. Thus, it may contribute to a reduction in the total ESD cost.

Keywords: Endoscopic submucosal dissection, Early gastric cancer, Hemostasis, Device, Splash M-knife

\footnotetext{
* Correspondence: esaki_saiseikai@yahoo.co.jp

${ }^{1}$ Division of Gastroenterology and Hepatology, Department of Medicine,

Nihon University School of Medicine, 1-6 Kanda-Surugadai, Chiyoda-ku,

Tokyo 101-8309, Japan

2Department of Gastroenterology, Kitakyushu Municipal Medical Center,

2-1-1 Bashaku, Kokurakita-ku, Kitakyushu, Fukuoka 802-0077, Japan

Full list of author information is available at the end of the article
}

(c) The Author(s). 2018 Open Access This article is distributed under the terms of the Creative Commons Attribution 4.0 International License (http://creativecommons.org/licenses/by/4.0/), which permits unrestricted use, distribution, and reproduction in any medium, provided you give appropriate credit to the original author(s) and the source, provide a link to the Creative Commons license, and indicate if changes were made. The Creative Commons Public Domain Dedication waiver (http://creativecommons.org/publicdomain/zero/1.0/) applies to the data made available in this article, unless otherwise stated. 


\section{Background}

Endoscopic submucosal dissection (ESD) has been widely accepted as a curative and minimally invasive treatment for gastric neoplasms [1-3]. However, bleeding during ESD remains a challenging complication, sometimes requiring replacement of devices to achieve hemostasis, thus increasing the difficulty of the procedure $[4,5]$. In the event of bleeding during the ESD procedure, the endo-knife itself is first used to obtain hemostasis. However, if there is difficulty in achieving hemostasis, we switch to using hemostatic forceps such as Coagrasper ${ }^{\ominus}$ (Coagrasper, FD-410LR; Olympus, Tokyo, Japan), which costs 15,000 JPY (136 USD). In addition, frequent use of hemostatic forceps may be associated with hypercoagulation, which causes thermal damage to the gastric wall, leading to delayed perforation $[6,7]$. In 2017, Tanaka et al. reported a 86\% (57/66) usage rate of hemostatic forceps during ESD [8], reinforcing the difficulty in achieving hemostasis with the endo-knife alone.

Recently, a new ESD device has been developed. Splash M-knife ${ }^{\circ}$ (DN-D2718A; HOYA Corp., Pentax, Tokyo, Japan) (M-knife), or simply M-knife, is a new multi-functional ESD device, designed to achieve complete ESD with a single device. Pictures of M-knife are shown in Fig. 1a-d. It is a needle-type knife, with the most notable feature being its hemostatic ability. On closure of the M-knife, a metal plate attached to the distal sheath assists with hemostasis. If the entire procedure can be conducted using the M-knife alone without the usage of hemostatic forceps, it may result in consequent cost reduction. However, there are no reports on the hemostatic ability of the M-knife in ESD. Here we report the results of our evaluation of its efficacy in comparison with that of the conventional needle-type knife in achieving hemostasis during ESD.

\section{Methods}

\section{Study design}

This study was a single-center retrospective cohort study without randomization. We collected and retrospectively reviewed data from medical records, endoscopic reports, and the database of ESD at Kitakyushu Municipal Medical Center, Fukuoka, Japan.

\section{Patients}

Between January 2012 and August 2016, ESD for early gastric cancer was performed on 445 patients at the Kitakyushu Municipal Medical Center. We excluded 15 patients with lesions in the remnant stomach or the gastric tube. We also excluded 27 patients in whom two lesions were simultaneously treated by ESD. We further excluded 249 patients who were treated by ESD using the insulated-tip or scissor-type knife. Finally, 149 patients who underwent ESD either by Flush Knife BT or Splash M-knife were enrolled in the study. Flush Knife BT was mainly used from January 2012 to June 2015 while Splash M-knife was used from July 2015 to August 2016. The flowchart of patient selection is shown in Fig. 2.

\section{Method of ESD \\ ESD procedure}

ESD-M was defined as ESD with M-knife, while ESD-F was defined as ESD with the conventional needle-type knife. We used Flush Knife BT (Fujifilm Co., Tokyo, Japan) $2.5 \mathrm{~mm}[9,10]$ as the conventional needle-type knife. ESD for early gastric cancer (EGC) was performed using a standard technique, as described in detail elsewhere $[1-3,5]$. Briefly, markings were placed around the lesion. Then, a mixture of equal parts of normal saline and $4 \%$ sodium hyaluronate with a small amount of epinephrine $(0.001 \mathrm{mg} / \mathrm{ml})$ and $0.8 \%$ indigo carmine was injected into the submucosal layer to lift up the lesion. After the injection, mucosal incision around the lesion and submucosal dissection were conducted with the Endo-knife. A VIO 300D or ICC 200 (ERBE Elektromedizin, GmbH, Tübingen, Germany) were used as the power sources for electrical cutting and coagulation. Marking and submucosal dissection were conducted in forced coagulation mode (30-40 W, effect; 2-3 in VIO300D, $40 \mathrm{~W}$ in ICC200). Mucosal incision was conducted in Endo Cut mode (effect 3, duration 3 in VIO300D, effect3 $80 \mathrm{~W}$ in ICC200). We defined expert operators in this study as those who had experience in performing at least 50 cases of ESD for EGC, and trainees as those who had experience in performing less than 50 cases of that. Six experts and 13 trainees

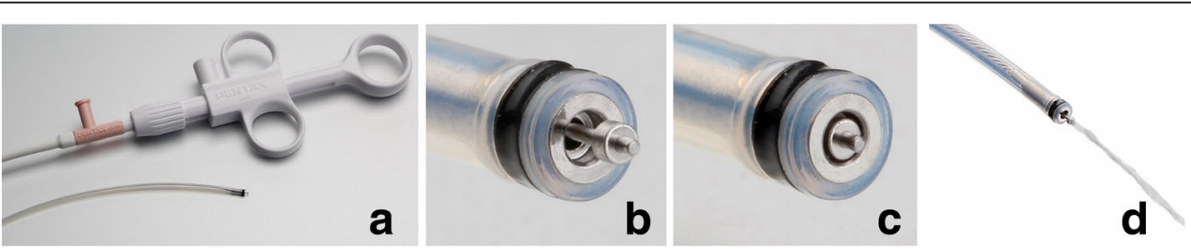

Fig. 1 a Splash M-knife is a needle-type knife, with a needle length of $2.0 \mathrm{~mm}$. b Open view of the tip of Splash M-knife. c Close view of the tip of Splash M-knife. A metal plate attached to the distal sheath helps hemostasis. d Splash M-knife has a water jet-assisted system to inject fluids through the tip of the knife 


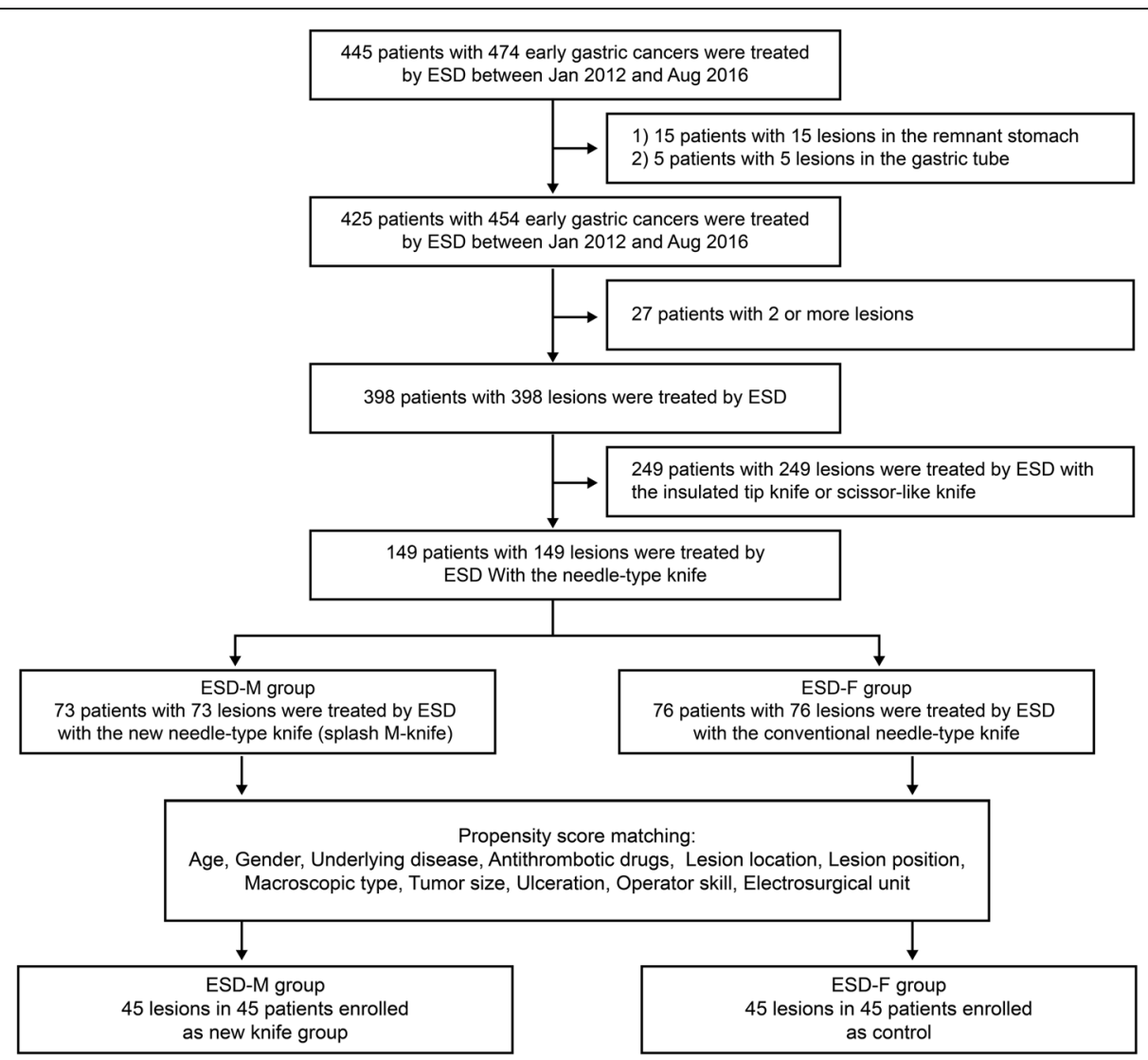

Fig. 2 Flowchart of patients and lesions enrolled in this study. ESD, endoscopic submucosal dissection; ESD-M, endoscopic submucosal dissection with splash-M knife; ESD-F, endoscopic submucosal dissection with Flush Knife BT

performed ESD in this study. All operators had used both knives at least 3 times before the study period, and therefore, were familiar with both the knives.

\section{Hemostasis procedure}

When bleeding or exposed vessels were detected, mainly during mucosal incision or submucosal dissection of the ESD procedure, hemostasis was carried out via coagulation with the tip of a needle-type knife. When we encountered any bleeding or detected any large vessels during ESD procedure, the initial hemostasis procedure was performed with the Endo-knife itself. We switched to use a hemostatic forceps when the initial threeminute hemostasis was not achieved. Coagrasper ${ }^{\circ}$ (Soft coagulation mode; 80-100 W, effect; 5-6 in VIO300D, $80 \mathrm{~W}$ in ICC200) was the most frequently used hemostatic forceps in this study.

\section{Outcome}

The primary endpoint in this study was the usage rate of the hemostatic forceps. The usage rate of the hemostatic forceps was defined as the percentage of lesions that required the use of hemostatic forceps at least once during the ESD procedure. According to the previous report, less than $20 \%$ of ESD using Flush Knife BT could be completed without the use of hemostatic forceps [8]. However, there were no data on the efficacy of M-knife in achieving hemostasis. We therefore hypothesized that $50 \%$ of ESD using M-knife could be completed without the use of hemostatic forceps, resulting in a 30\% reduction in the usage of hemostatic forceps in this study. By assuming a 5\% significance level and a statistical power of $80 \%$, power analysis estimated that a minimum number of 39 patients would be required in each group. The secondary endpoints were procedure time for ESD, en bloc and complete resection rates, and adverse events rates (perforation and post-procedural bleeding). Procedure time for ESD was measured from the first injection after the mucosal marking to the completion of submucosal dissection. En bloc resection was defined as the whole tumor being removed in one-piece fashion. Complete resection was defined as the whole tumor being removed in one-piece fashion with tumor-free lateral and vertical margins. Perforation was diagnosed if extramural organ or fat protruding through the gastric wall was visualized during endoscopy, or if free air was seen on abdominal radiography or CT imaging. Post-procedural bleeding was diagnosed on the basis of clinical symptoms 
such as melena or hematemesis, or a decrease of $>2 \mathrm{~g} / \mathrm{dL}$ in hemoglobin level after ESD, or bleeding proven with routine or emergency second-look endoscopy.

\section{Statistics}

There were potential confounding biases between the two groups due to the retrospective nature of the study. In previous reports, including meta-analyses, large lesions, ulcerative (scar) lesions, lesions in the lesser curvature, lesions in the upper or middle position, flat or depressed morphology, the presence of gastric malignancy, male gender, antithrombotic drugs use, patients with underlying diseases (cardiomyopathy/cirrhosis/ chronic kidney disease), and skill of operators were identified as prognostic factors for perioperative bleeding or technical difficulty of ESD [11-24]. Differences in these factors between the two groups might affect clinical outcomes. To compensate for these differences, we calculated propensity scores [25] using a logistic regression model (Fig. 2) for the following covariates: age ( $\geqq 75$ years vs $<75$ years), gender (male vs female), underlying disease (none vs with cardiomyopathy or cirrhosis), antithrombotic drugs use (not receiving or discontinuation vs continuation), tumor size ( $\geqq 21 \mathrm{~mm}$ vs $<21 \mathrm{~mm})$, lesion location (in the upper or middle third of the stomach vs in the lower stomach), lesion position (in the lessor curvature of the stomach vs other positions), macroscopic type (flat or depressed vs protruding), ulceration (presence vs absence), skill of operators (expert vs trainee), and electrosurgical unit (VIO300D vs ICC200). Patients with similar propensity scores were matched in a 1:1 ratio from the ESD-M and ESD-F groups. Calipers (0.21) with a width equal to 0.25 of the standard deviation of the logit of the propensity score were used. We estimated the area under the receiver operating characteristics curve to validate the model in this study. The area under the curve was 0.744 and had predictive power. The two groups were evaluated in terms of the absolute standardized differences before and after matching to ensure balance of propensity scoring. Characteristics were considered to be in balance if the absolute standardized difference (ASD) was within $1.96 \sqrt{ } 2 / \mathrm{n}$ after matching [26]. In this study, all ASDs were within $1.96 \sqrt{2} / \mathrm{n}$ after matching. To analyze the baseline characteristics of the patients and outcomes of this study, The Mann-Whitney $U$ test or $t$ test was used for continuous data, whereas the $x^{2}$ test and Fisher's exact test were used for categorical data. Values of $p<0.05$ were considered statistically significant for all tests. All analyses were performed using the JMP Pro 11.0 software.

\section{Ethics}

This study was conducted in accordance with the Declaration of Helsinki. This study protocol was approved by the institutional review board of Kitakyushu Municipal Medical Center on November 18, 2016. Written informed consent was obtained from all patients before ESD.

\section{Results \\ Baseline characteristics and outcomes before propensity score matching}

The baseline characteristics of the 149 patients and lesions are shown in Table 1. ESD-M was conducted in 73 patients and ESD-F in 76 . The percentage of expert operators was significantly higher in the ESD-M group than in the ESD-F group. There were no significant differences between the two groups with respect to other factors. Treatment outcomes before propensity matching are shown in Table 2.

En bloc resection was successfully performed in all patients from both groups. The overall rate of complete resection was $97.3 \%$, with no significant difference between the two groups. Perforation occurred in only one patient in ESD-F. In contrast, post-procedural bleeding occurred in nine patients. Four of these were in ESD-M and the remaining five in ESD-F. Although three patients required blood transfusion, all bleeding was successfully controlled using endoscopic procedures with hemostatic forceps, and no patients required open surgical treatment. There were no treatment-related deaths. Of the 73 patients in the ESD-M group, hemostatic forceps were used during the ESD procedure in 10 patients (13.7\%), compared with 65 of the 76 patients $(85.5 \%)$ in the ESD-F group. Furthermore, hemostatic forceps were only required in one $(3.8 \%)$ of the 26 ESD procedures performed by trainees.

\section{Treatment outcomes after propensity score matching} The matching factors between ESD-M and ESD-F after propensity score matching are shown in Table 3 . Propensity score matching analysis created 45 matched pairs, which was an adequate number for statistical requirements. The treatment outcomes are shown in Table 4. Adjusted comparisons between the two groups showed a significantly lower usage rate of hemostatic forceps in the ESD-M group compared to the ESD-F group $(6.7 \%$ vs $84.4 \%, p<0.001)$. Treatment outcomes were similar in the two groups, (complete resection rate: $95.6 \%$ vs $100 \%, p=0.49$; median procedure time: 74.0 min vs 71.0 min, $p=0.90$ in the ESD-M and ESD-F groups, respectively). With respect to adverse events, there were no perforations in either group; postprocedure bleeding was $2.2 \%$ vs $2.2 \%, p=1$ in the ESD$\mathrm{M}$ and ESD-F groups, respectively; and there were no treatment-related deaths. The en bloc resection rate was $100 \%$ in both groups as before matching. 
Table 1 Baseline characteristics of the 149 patients who underwent ESD

\begin{tabular}{|c|c|c|c|c|c|}
\hline & Total $n=149$ & ESD-M $n=73$ & ESD-F $n=76$ & $p$ value & ASD \\
\hline \multicolumn{6}{|l|}{ Age (years) } \\
\hline Mean \pm SD & $73.3 \pm 8.6$ & $73.0 \pm 8.4$ & $73.6 \pm 8.7$ & $0.67^{\natural}$ & 0.0702 \\
\hline Median (range) & $74(52-91)$ & $74(52-91)$ & $74(52-90)$ & $0.67^{5}$ & \\
\hline Gender & & & & $0.4^{\ddagger}$ & \\
\hline Male & $97(65.1 \%)$ & $45(61.6 \%)$ & $52(68.4 \%)$ & & 0.143 \\
\hline Female & $52(34.9 \%)$ & $28(38.4 \%)$ & $24(31.6 \%)$ & & 0.143 \\
\hline Underlying disease & & & & $0.49^{\ddagger}$ & \\
\hline None & $132(88.6 \%)$ & $66(90.4 \%)$ & $66(86.8 \%)$ & & 0.113 \\
\hline Cardiomyopathy or cirrhosis & $17(11.4 \%)$ & $7(9.6 \%)$ & $10(13.2 \%)$ & & 0.143 \\
\hline Antithrombotic drugs & & & & $0.091^{\ddagger}$ & \\
\hline None or discontinuation & $143(96.0 \%)$ & $72(98.6 \%)$ & $71(93.4 \%)$ & & 0.268 \\
\hline Continuation & $6(4.0 \%)$ & $1(1.4 \%)$ & $5(6.6 \%)$ & & 0.268 \\
\hline Location of lesions & & & & $0.055^{+}$ & \\
\hline Upper & $24(16.1 \%)$ & $12(16.4 \%)$ & $12(15.8 \%)$ & & 0.0163 \\
\hline Middle & $54(36.2 \%)$ & $33(45.2 \%)$ & $21(27.6 \%)$ & & 0.372 \\
\hline Lower & $71(47.7 \%)$ & $28(38.4 \%)$ & $43(56.6 \%)$ & & 0.371 \\
\hline Position of lesions & & & & $0.44^{\dagger}$ & \\
\hline Lesser curvature & $60(40.2 \%)$ & $30(41.1 \%)$ & $30(39.5 \%)$ & & 0.0326 \\
\hline Greater curvature & $38(25.5 \%)$ & $22(30.1 \%)$ & $16(21.1 \%)$ & & 0.207 \\
\hline Anterior wall & 29 (19.5\%) & $11(15.1 \%)$ & $18(23.7 \%)$ & & 0.219 \\
\hline Posterior wall & $22(14.8 \%)$ & $10(13.7 \%)$ & $12(15.8 \%)$ & & 0.0592 \\
\hline Morphology & & & & $0.27^{+}$ & \\
\hline Protruding & $55(36.9 \%)$ & $30(41.1 \%)$ & $25(32.9 \%)$ & & 0.170 \\
\hline Flat & $1(0.7 \%)$ & $1(1.4 \%)$ & $0(0 \%)$ & & 0.169 \\
\hline Depressed & $93(63.4 \%)$ & $42(57.5 \%)$ & $51(67.1 \%)$ & & 0.199 \\
\hline Histology & & & & $0.68^{\ddagger}$ & \\
\hline Differentiated & $144(96.6 \%)$ & 70 (95.9\%) & 74 (97.4\%) & & 0.0834 \\
\hline Undifferentiated & $5(3.4 \%)$ & $3(4.1 \%)$ & $2(2.6 \%)$ & & 0.0834 \\
\hline \multicolumn{6}{|l|}{ Lesion size (mm) } \\
\hline Mean \pm SD & $16.6 \pm 10.0$ & $17.2 \pm 9.3$ & $16.1 \pm 10.6$ & $0.49^{\prime \prime}$ & 0.110 \\
\hline Median (range) & $15(3-77)$ & $15(3-40)$ & $14(4-77)$ & $0.27^{\S}$ & \\
\hline \multicolumn{6}{|l|}{ Specimen size (mm) } \\
\hline Mean \pm SD & $39.0 \pm 12.0$ & $39.8 \pm 11.6$ & $38.2 \pm 12.4$ & $0.42^{\prime \prime}$ & 0.133 \\
\hline Median (range) & $36(17-110)$ & $40(17-75)$ & $35(20-110)$ & $0.35^{\S}$ & \\
\hline Depth & & & & $0.68^{\dagger}$ & \\
\hline pT1a & $132(88.6 \%)$ & $63(86.3 \%)$ & $69(90.8 \%)$ & & 0.0724 \\
\hline pT1b1 & $7(4.7 \%)$ & $4(5.5 \%)$ & $3(3.9 \%)$ & & 0.0757 \\
\hline pT1b2 & $10(6.7 \%)$ & $6(8.2 \%)$ & $4(5.3 \%)$ & & 0.116 \\
\hline Presence of ulceration & $17(11.4 \%)$ & $10(13.7 \%)$ & $7(9.2 \%)$ & $0.45^{\ddagger}$ & 0.142 \\
\hline Operator level & & & & $<0.001^{\ddagger}$ & \\
\hline Experts & $70(47.0 \%)$ & $47(64.4 \%)$ & $23(30.3 \%)$ & & 0.727 \\
\hline Electrosurgical unit & & & & $0.009^{\ddagger}$ & \\
\hline $\mathrm{VIO} 300 \mathrm{D}$ & $128(85.9 \%)$ & $57(78.1 \%)$ & $71(93.4 \%)$ & & 0.450 \\
\hline ICC200 & $21(14.1 \%)$ & 16 (21.9\%) & $5(6.6 \%)$ & & 0.450 \\
\hline
\end{tabular}

ESD endoscopic submucosal dissection, ESD-M endoscopic submucosal dissection with Splash-M knife, ESD- $F$ endoscopic submucosal dissection with Flush Knife $\mathrm{BT}, \mathrm{SD}$ standard deviation ASD absolute standardized difference

$p$ value was calculated using the $X^{2}$ test ${ }^{\dagger}$ and Fisher's exact test ${ }^{\ddagger}$ for categorical data

$p$ value was calculated using the $\mathrm{t}$ test ${ }^{\natural}$ and the Mann-Whitney $\mathrm{U}$ test ${ }^{\S}$ for continuous data

pT1a, tumor invasion is within mucosa; pT1b1, tumor invasion is within $0.5 \mathrm{~mm}$ of the muscularis mucosae; pT1b2, tumor invasion is $0.5 \mathrm{~mm}$ or deeper into the muscularis mucosae 
Table 2 Treatment outcomes of the ESD before propensity score matching

\begin{tabular}{|c|c|c|c|c|}
\hline & Total $n=149$ & ESD-M $n=73$ & ESD-F $n=76$ & $p$ value \\
\hline Usage rate of hemostatic forceps & 75 (50.3\%) & $10(13.7 \%)$ & $65(85.5 \%)$ & $<0.001^{*} \neq$ \\
\hline Expert & $28 / 70(40.0 \%)$ & 9/47 (19.1\%) & 19/23 (82.6\%) & $<0.001^{*} \neq$ \\
\hline Trainee & $47 / 79$ (59.5\%) & $1 / 26(3.8 \%)$ & $46 / 53(86.8 \%)$ & $<0.001^{*} \neq$ \\
\hline \multicolumn{5}{|l|}{ Procedure time(min) } \\
\hline Mean \pm SD & $80.1 \pm 51.1$ & $83.8 \pm 49.7$ & $76.7 \pm 52.4$ & $0.4^{9}$ \\
\hline Median(range) & $70(7-410)$ & $74.0(7-252)$ & $69.5(18-410)$ & $0.3^{\S}$ \\
\hline En bloc resection & 149 (100\%) & $73(100 \%)$ & $76(100 \%)$ & $1^{\ddagger}$ \\
\hline Complete resection & $145(97.3 \%)$ & 70 (95.9\%) & 75 (98.7\%) & $0.36^{\ddagger}$ \\
\hline Perforation & $1(0.7 \%)$ & $0(0 \%)$ & $1(1.3 \%)$ & $1^{\ddagger}$ \\
\hline Post-procedure bleeding & $9(6.0 \%)$ & $4(5.5 \%)$ & $5(6.6 \%)$ & $1^{\ddagger}$ \\
\hline
\end{tabular}

ESD endoscopic submucosal dissection, ESD-M endoscopic submucosal dissection with Splash M-knife, ESD-F endoscopic submucosal dissection with Flush Knife BT, SD standard deviation

$p$ value was calculated using Fisher's exact test ${ }^{\ddagger}$ for categorical data

$p$ value was calculated using the $\mathrm{t}$ test ${ }^{\natural}$ and the Mann-Whitney $\mathrm{U}$ test ${ }^{\S}$ for continuous data

significant value

\section{Discussion}

To our knowledge, this is the first report describing the efficacy of this new needle-type device, the Mknife, compared to that of Flush Knife BT which is one of the conventional needle-type knives. ESD with M-knife was associated with a significantly lower usage rate of hemostatic forceps. In addition, ESD with M-knife achieved similar technical outcomes to those of Flush Knife BT with no increase in adverse events.

There are two conventional types of knives used in ESD: the needle-type knife and the insulated-tip knife [27]. In the needle-type knives, there were two major developments before the advent of the M-knife. One was the water jet-assisted system, which allowed injection of fluids through the tip of knife during ESD procedure. This allowed for fluid injection without changing instruments, significantly shortening the procedure time [28-30]. The other development was the attachment of a ball-tip to the tip of the knife, improving its operability and increasing hemostatic efficacy. In this study, we used the Flush Knife BT, which has both of these features, as a conventional needle-type knife $[9,10]$. The ball-tip enables easy removal of tissues during incision or dissection. Furthermore, by attaching a ball-tip, the diameter of the knife is expanded up to $0.9 \mathrm{~mm}$, facilitating hemostasis. Although Flush Knife BT improves hemostatic efficacy with these two developments compared to standard Flush Knife, we still sometimes encountered cases wherein hemostasis was unsuccessful

Table 3 Matching factors between the Splash M-knife and control groups after propensity score matching

\begin{tabular}{|c|c|c|c|c|}
\hline & $\mathrm{ESD}-\mathrm{M} n=45$ & ESD-F $n=45$ & $p$ value & ASD \\
\hline \multicolumn{5}{|l|}{ Variable matching between groups } \\
\hline Age, $y$; mean $\pm S D$ & $73.5 \pm 8.68$ & $73.0 \pm 8.95$ & $0.802^{\natural}$ & 0.0454 \\
\hline Gender; Male/Female & $27 / 18$ & $25 / 20$ & $0.831^{\ddagger}$ & 0.0464 \\
\hline Underlying disease; No/Yes & $41 / 4$ & $41 / 4$ & $1^{\ddagger}$ & 0 \\
\hline Antithrombotic drugs; No/Yes & $44 / 1$ & $44 / 1$ & $1^{\neq}$ & 0 \\
\hline Tumor size, $\mathrm{mm}$ mean $\pm \mathrm{SD}$ & $17.0 \pm 9.46$ & $16.8 \pm 12.2$ & $0.923^{\natural}$ & 0.0183 \\
\hline Location of lesions; Upper or Middle/Lower & $26 / 19$ & $26 / 19$ & $1^{\ddagger}$ & 0 \\
\hline Position of lesions; Lesser curvature/others & $19 / 26$ & $18 / 27$ & $1^{\neq}$ & 0.0908 \\
\hline Macroscopic type; Flat or depressed/ protruding & $27 / 18$ & 29/16 & $0.828^{\ddagger}$ & 0.0918 \\
\hline Presence of ulceration & 4 & 4 & $1^{\neq}$ & 0 \\
\hline Operator level; expert/trainee & $22 / 23$ & $22 / 23$ & $1^{\ddagger}$ & 0 \\
\hline Electrosurgical unit; VIO 300D/ICC 200 & $40 / 5$ & $40 / 5$ & $1^{\neq}$ & 0 \\
\hline
\end{tabular}

ESD-M endoscopic submucosal dissection with Splash M-knife, ESD-F endoscopic submucosal dissection with Flush Knife BT, SD standard deviation, $A S D$ absolute standardized difference

$p$ value was calculated using Fisher's exact test ${ }^{\ddagger}$ for categorical data

$p$ value was calculated using the test " for continuous data 
Table 4 Treatment outcomes between the Splash M-knife and control groups after propensity score matching

\begin{tabular}{llll}
\hline & ESD-M $n=45$ & ESD-F $n=45$ & $p$ value \\
\hline $\begin{array}{l}\text { Usage rate of hemostatic forceps } \\
\text { Procedure time(min) }\end{array}$ & $3(6.7 \%)$ & $38(84.4 \%)$ & $<.001^{*} \neq$ \\
$\quad$ Mean \pm SD & $83.7 \pm 48.5$ & $84.2 \pm 62.3$ & $0.961^{\natural}$ \\
$\quad$ Median(range) & $74.0(21-240)$ & $71.0(18-410)$ & $0.90^{\S}$ \\
En bloc resection & $44(100 \%)$ & $44(100 \%)$ & $1^{\ddagger}$ \\
Complete resection & $43(95.6 \%)$ & $44(100 \%)$ & $0.494^{\ddagger}$ \\
Perforation & $0(0 \%)$ & $0(0 \%)$ & $1^{\ddagger}$ \\
Post-procedure bleeding & $1(2.2 \%)$ & $1(2.2 \%)$ & $1^{\ddagger}$ \\
\hline
\end{tabular}

ESD-M endoscopic submucosal dissection with Splash M-knife, ESD-F endoscopic submucosal dissection with Flush Knife BT, SD standard deviation $p$ value was calculated using Fisher's exact test ${ }^{*}$ for categorical data

$p$ value was calculated using the $\mathrm{t}$ test ${ }^{\natural}$ and the Mann-Whitney $\mathrm{U}$ test ${ }^{\S}$ for continuous data *significant value

using this endo-knife alone, and consequently, hemostatic forceps were required $[8,10]$.

The M-knife, which also has the above two features, is developed to overcome the problem of hemostasis. A metal plate, $1.8 \mathrm{~mm}$ in diameter, is attached to the distal sheath of this knife. This is twice as long as the ball-tip of the Flush Knife BT, and the contact area of the metal plate is four times larger. When the M-knife is closed during the procedure, this metal plate facilitates hemostasis. The significantly different outcome in terms of the hemostatic ability of these 2 knives in this study was thought to be due to the difference in the device structure.

In this study, we selected the usage rate of hemostatic forceps as a primary endpoint to evaluate the hemostatic ability of the ESD devices. The $86 \%$ usage rate of hemostatic forceps reported by Tanaka et al. [8] is similar to that in the Flush Knife BT group in this study. In contrast, ESD was completed with a single knife without hemostatic forceps in $86.7 \%$ of patients in the M-knife group. Although ESD has the benefit of a high en bloc resection rate even for larger or ulcerative lesions in any part of the stomach, as well as accurate pathological evaluation [1-3], the cost of ESD is higher than that of endoscopic mucosal resection (EMR). This is one of the disadvantages of ESD in the treatment of early gastric cancer compared to EMR. The cost of the Coagrasper ${ }^{\oplus}$ hemostatic forceps is about 15,000 yen. A 50\% reduction in its use would result in a less costly hemostasis during ESD procedure. Using the M-knife may thus result in a reduction of total ESD cost due to a lower usage rate of hemostatic forceps.

We did not restrict the number of hemostatic attempts with the needle-type knife, although other studies have done so [4]. Thus, the number of hemostatic attempts with the M-knife may have been greater than that in the conventional needle-type knife group. However, neither procedure time nor perforation rate was significantly different between the two groups. Hemostatic attempts with the endo-knife alone seems to have few disadvantages either in the length of procedure time or risk of perforation.

We included patients treated not only by experts but also by trainees in this study. Before matching, trainees conducted 35\% (26/73) of ESD with M-knife and hemostatic forceps was used in only one case. Therefore, no special skill is required for hemostasis with the M-knife, which is useful not only for experts but also for trainees.

This study has several limitations. Firstly, this was not a prospective randomized controlled trial. It thus has the limitations of retrospective studies, as all relevant data may not be available in detail, even though we conducted a propensity score matching analysis. Secondly, this study was conducted in a single center with a restricted number of study samples. A multicenter trial will be performed to determine the advantage of using the M-knife during ESD procedure in the near future. Thirdly, Flush Knife BT was used in the initial phase of this study while Splash M-knife was used during the late phase. The possibility that an institutional learning curve, if any, that could affect the outcomes of the study cannot be denied. Fourthly, the initial hemostasis procedure was performed with Endoknife. We switched to use a hemostatic forceps when the initial three-minute hemostasis was not achieved. This might be affected by certain factors including the operator's preference, experience and skill and the size of the vessels; some of which might not be fully compensated for by the propensity score matching analysis. Finally, this study compared the efficacy of the M-knife to that of the Flush Knife BT, which is one of the conventional needle-type knives. Further studies are required to compare clinical outcomes of M-knife not only to other needle-type knives but also to other type of endo-knives including the insulated-tip knife and grasping-type knife [31, 32]. 


\section{Conclusions}

Compared to the Flush Knife BT, Splash-M knife appeared to reduce the usage of hemostatic forceps during ESD procedure with no increase in adverse events. Thus, it may contribute to a reduction in the total ESD cost. Furthermore, ESD with Splash M-knife is feasible even for trainees.

\section{Abbreviations}

ASD: Absolute standardized difference; EGC: Early gastric cancer; ESD: Endoscopic submucosal dissection; ESD-F: Endoscopic submucosal dissection with Flush Knife BT; ESD-M: Endoscopic submucosal dissection with M-knife; M-knife: Splash M-knife ${ }^{\oplus}$ : SD: Standard deviation

\section{Acknowledgements}

Not applicable

\section{Funding}

Not applicable

\section{Availability of data and materials}

The datasets used and/or analyzed during the current study are available from the corresponding author on reasonable request.

\section{Authors' contributions}

ME, SS; conception and design, drafting of the article, critical revision of the article for important intellectual content. YH, AY, SA, TH, HO; analysis and interpretation of the data. HA; critical revision of the manuscript. El, YO: study supervision. All authors read and approved the final manuscript.

\section{Ethics approval and consent to participate}

This study was conducted in accordance with the Declaration of Helsinki. This study protocol was approved by the institutional review board of Kitakyushu Municipal Medical Center on November 18, 2016. Written informed consent was obtained from all patients before ESD.

\section{Consent for publication}

Not applicable

\section{Competing interests}

The authors declare that they have no competing interests.

\section{Publisher's Note}

Springer Nature remains neutral with regard to jurisdictional claims in published maps and institutional affiliations.

\section{Author details}

'Division of Gastroenterology and Hepatology, Department of Medicine, Nihon University School of Medicine, 1-6 Kanda-Surugadai, Chiyoda-ku, Tokyo 101-8309, Japan. ${ }^{2}$ Department of Gastroenterology, Kitakyushu Municipal Medical Center, 2-1-1 Bashaku, Kokurakita-ku, Kitakyushu, Fukuoka 802-0077, Japan. ${ }^{3}$ Department of Medicine and Bioregulatory Science, Graduate School of Medical Sciences, Kyushu University, 3-1-1 Maidashi, Higashi-ku, Fukuoka 812-8582, Japan.

Received: 18 October 2017 Accepted: 23 February 2018

Published online: 27 February 2018

\section{References}

1. Rembacken BJ, Gotoda T, Fujii T, Axon AT. Endoscopic mucosal resection. Endoscopy. 2001;33(8):709-18.

2. Soetikno RM, Gotoda T, Nakanishi Y, Soehendra N. Endoscopic mucosal resection. Gastrointest Endosc. 2003:57(4):567-79.

3. Soetikno R, Kaltenbach T, Yeh R, Gotoda T. Endoscopic mucosal resection for early cancers of the upper gastrointestinal tract. J Clin Oncol. 2005; 23(20):4490-8.

4. Toyonaga T, Nishino E, Man IM, East JE, Azuma T. Principles of quality controlled endoscopic submucosal dissection with appropriate dissection level and high quality resected specimen. Clin Endosc. 2012;45(4):362-74.
5. Yamamoto S, Uedo N, Ishihara R, Kajimoto N, Ogiyama H, Fukushima Y, et al. Endoscopic submucosal dissection for early gastric cancer performed by supervised residents: assessment of feasibility and learning curve. Endoscopy. 2009:41(11):923-8.

6. Hanaoka N, Uedo N, Ishihara R, Higashino K, Takeuchi Y, Inoue T, et al. Clinical features and outcomes of delayed perforation after endoscopic submucosal dissection for early gastric cancer. Endoscopy. 2010;42(12): 1112-5.

7. Ikezawa K, Michida T, Iwahashi K, Maeda K, Naito M, Ito T, et al. Delayed perforation occurring after endoscopic submucosal dissection for early gastric cancer. Gastric Cancer. 2012;15(1):111-4.

8. Tanaka S, Toyonaga T, Morita Y, Ishida T, Hoshi N, Grimes KL, et al. Efficacy of a new hemostatic forceps during gastric endoscopic submucosal dissection: a prospective randomized controlled trial. J Gastroenterol Hepatol. 2017:32(4):846-51.

9. Toyonaga T, Man-i M, Fujita T, East J, Coumaros D, Morita Y, et al. Endoscopic submucosal dissection using the flush knife and the flush knife BT. Tech Gastrointest Endosc. 2011;13:84-90.

10. Toyonaga T, Man IM, Fujita T, Nishino E, Ono W, Morita Y, et al. The performance of a novel ball-tipped flush knife for endoscopic submucosal dissection: a case-control study. Aliment Pharmacol Ther. 2010;32(7):908-15.

11. Chung IK, Lee JH, Lee SH, Kim SJ, Cho JY, Cho WY, et al. Therapeutic outcomes in 1000 cases of endoscopic submucosal dissection for early gastric neoplasms: Korean ESD study group multicenter study. Gastrointest Endosc. 2009;69(7):1228-35.

12. Imagawa A, Okada H, Kawahara Y, Takenaka R, Kato J, Kawamoto H, et al. Endoscopic submucosal dissection for early gastric cancer: results and degrees of technical difficulty as well as success. Endoscopy. 2006:38(10):987-90.

13. Nagata S, Jin YF, Tomoeda M, Kitamura M, Yuki M, Yoshizawa H, et al. Influential factors in procedure time of endoscopic submucosal dissection for gastric cancer with fibrotic change. Dig Endosc. 2011;23(4):296-301.

14. Kim JH, Nam HS, Choi CW, Kang DH, Kim HW, Park SB, et al. Risk factors associated with difficult gastric endoscopic submucosal dissection: predicting difficult ESD. Surg Endosc. 2017;31(4):1617-26.

15. Yoon JY, Shim CN, Chung SH, Park W, Chung H, Lee H, et al. Impact of tumor location on clinical outcomes of gastric endoscopic submucosal dissection. World J Gastroenterol. 2014;20(26):8631-7.

16. Yoshida M, Kakushima N, Mori K, Igarashi K, Kawata N, Tanaka M, et al. Learning curve and clinical outcome of gastric endoscopic submucosal dissection performed by trainee operators. Surg Endosc. 2016;31(9):3614-22.

17. Oda I, Odagaki T, Suzuki H, Nonaka S, Yoshinaga S. Learning curve for endoscopic submucosal dissection of early gastric cancer based on trainee experience. Dig Endosc. 2012;24(Suppl 1):129-32.

18. Sun C, Zheng Z, Wang B. Learning curve for endoscopic submucosal dissection of gastric submucosal tumors: is it more difficult than it may seem? J Laparoendosc Adv Surg Tech A. 2014;24(9):623-7.

19. Choi IJ, Kim CG, Chang HJ, Kim SG, Kook MC, Bae JM. The learning curve for EMR with circumferential mucosal incision in treating intramucosal gastric neoplasm. Gastrointest Endosc. 2005;62(6):860-5.

20. Suk KT, Ham YL, Baik GH, Sung HT, Sohn KM, Kim DY, et al. Efficacy of partial endoscopic submucosal dissection with polypectomy of gastric neoplasm during a learning period. Hepato-Gastroenterology. 2013;60(128):2107-12.

21. Hong KH, Shin SJ, Kim JH. Learning curve for endoscopic submucosal dissection of gastric neoplasms. Eur J Gastroenterol Hepatol. 2014;26(9):949-54.

22. Yamamoto $Y$, Fujisaki J, Ishiyama A, Hirasawa T, Igarashi M. Current status of training for endoscopic submucosal dissection for gastric epithelial neoplasm at cancer institute hospital, Japanese Foundation for Cancer Research, a famous Japanese hospital. Dig Endosc. 2012;24(Suppl 1):148-53.

23. Libanio D, Costa MN, Pimentel-Nunes P, Dinis-Ribeiro M. Risk factors for bleeding after gastric endoscopic submucosal dissection: a systematic review and meta-analysis. Gastrointest Endosc. 2016;84(4):572-86.

24. Jang JS, Choi SR, Graham DY, Kwon HC, Kim MC, Jeong JS, et al. Risk factors for immediate and delayed bleeding associated with endoscopic submucosal dissection of gastric neoplastic lesions. Scand J Gastroenterol. 2009;44(11):1370-6.

25. D'Agostino RB Jr. Propensity score methods for bias reduction in the comparison of a treatment to a non-randomized control group. Stat Med. 1998:17(19):2265-81.

26. Austin PC. Balance diagnostics for comparing the distribution of baseline covariates between treatment groups in propensity-score matched samples. Stat Med. 2009;28(25):3083-107. 
27. Bhatt A, Abe S, Kumaravel A, Vargo J, Saito Y. Indications and techniques for endoscopic submucosal dissection. Am J Gastroenterol. 2015;110(6):784-91.

28. Zhou PH, Schumacher B, Yao LQ, Xu MD, Nordmann T, Cai MY, et al. Conventional vs. waterjet-assisted endoscopic submucosal dissection in early gastric cancer: a randomized controlled trial. Endoscopy. 2014;46(10): 836-43.

29. Schumacher B, Charton JP, Nordmann T, Vieth M, Enderle M, Neuhaus H. Endoscopic submucosal dissection of early gastric neoplasia with a water jet-assisted knife: a western, single-center experience. Gastrointest Endosc. 2012;75(6):1166-74.

30. Tatsumi K, Uedo N, Ishihara R, Yamamoto S, Yamamoto S, Masuda E, et al. A water-jet videoendoscope may reduce operation time of endoscopic submucosal dissection for early gastric cancer. Dig Dis Sci. 2012;57(8):2122-9.

31. Ono H, Hasuike $\mathrm{N}$, Inui $\mathrm{T}$, Takizawa $\mathrm{K}$, Ikehara $\mathrm{H}$, Yamaguchi $\mathrm{Y}$, et al. Usefulness of a novel electrosurgical knife, the insulation-tipped diathermic knife-2, for endoscopic submucosal dissection of early gastric cancer. Gastric Cancer. 2008;11(1):47-52.

32. Akahoshi K, Akahane H, Motomura Y, Kubokawa M, Itaba S, Komori K, et al. A new approach: endoscopic submucosal dissection using the clutch cutter(R) for early stage digestive tract tumors. Digestion. 2012;85(2):80-4.

\section{Submit your next manuscript to BioMed Central} and we will help you at every step:

- We accept pre-submission inquiries

- Our selector tool helps you to find the most relevant journal

- We provide round the clock customer support

- Convenient online submission

- Thorough peer review

- Inclusion in PubMed and all major indexing services

- Maximum visibility for your research

Submit your manuscript at www.biomedcentral.com/submit 